\title{
Associative rigidity in free and controlled association
}

\author{
STEFAN SLAK, HENRY TONEY, and NANCY MARIK \\ University of Toledo, Toledo, Ohio 43606
}

\begin{abstract}
The purpose of the study was to investigate the feasibility of repetitiveness of associations to the same stimulus words as a measure of associative rigidity and to determine the correlation between rigidity scores in free association and controlled association tasks. One hundred and twenty-seven subjects were given a free association task first, followed by a controlled association task with subordinate concepts as the required responses. In both tasks, each test word was presented five times in the entire list. The number of different responses to the same stimulus word were counted and summed over 12 test words. Higher response variability was indicative of lower associative rigidity level. The product-moment correlation between the two tasks was .626, signifying a common factor of rigidity in free and controlled association tasks. Repetitiveness of the same associative response to the same stimulus was interpreted as a sensible measure of associative rigidity or stereotypy.
\end{abstract}

Slak, Shaffer, and Barone (1982) proposed the information-theoretic measure of redundancy in a randomized or spontaneous sequence of responses as a possible measure of sequential behavioral stereotypy, characterized by "patterning, repetitiveness of patterning, and reduced variability of responding." Stereotypy can be viewed as synonymous with rigidity, which is the opposite of flexibility. In production of discrete verbal associative responses (as distinguished from continuous sequencing of responses), associative rigidity can be viewed as a tendency toward recurrence of the same associations (response words) to the same stimulus words in the same subjects, whereas associative flexibility can be understood as the opposite tendency: occurrence of different responses to repeated presentation of the stimulus words displaying greater withinsubjects responses variability.

Johnson (1973) administered the Kent-Rosanoff word association test twice to the same subjects, 1 week apart. Instruction to repeat the same associative responses the second time resulted in about $10 \%$ higher number of repetitions than instruction to give the first associate. However, Johnson did not perceive this kind of repetition score in the original association task as an indicator of associative rigidity.

The purpose of the present study is to use repeated presentation of stimulus words in both free and controlled association to obtain a measure of associative rigidity in terms of the number of different responses to the same stimulus words in the same subjects and to correlate the two association tests to determine whether there is a common factor of associative rigidity operating under conditions of free and controlled association.

\section{METHOD}

A total of 127 undergraduate college students, 55 males and 72 females, served as subjects.

Two lists of 72 words, a free association list and a controlled association list, were prepared, each consisting of 12 test words repeated five times (giving a total of 60 ), plus 10 filler words and 2 practice words. The words in each list were chosen from the norms of Paivio, Yuille, and Madigan (1968). Free association test words were chosen randomly (e.g., "picture," "thief," "shame"). The controlled association words were those words from the norms denoting categories (e.g., "animal," "profession," "beverage"). The test words were chosen in such a way that each controlled association word was matched with one free association word with respect to meaningfulness and imagery value within an error range of \pm .5 in order to assure nearly the same average and dispersion of imagery and meaningfulness values in both lists.

The sequence of words in each list was random, with three restrictions: (1) The two practice words appeared first, (2) test words appeared five times in the list, and (3) there were at least two other words between two identical test words. Packets of slips of paper, $4.25 \times 5.50$ in., were prepared together with pencils for subjects' use.

Subjects were run in groups of 4-20, first in the free association condition and then, after a 5-min pause, in the controlled association condition. The whole test, including instruction time, took about $50 \mathrm{~min}$.

The words were read to the subjects at about 10 -sec intervals. In the free association condition, the subjects were instructed to respond in writing with the first word that came to mind. In the controlled association condition, subjects were instructed to respond with the first instance of the category (or subordinate concept) designated by the stimulus word. They were given packets of 72 slips of paper and instructed to write $M$ or $F$ on the top sheets, designating their sex. The top slip also contained the subject number and condition code.

Before each stimulus word was presented, subjects were given the serial number of the word, which they wrote down on the top of the slip of paper ( 0 and 00 for practice words, and 
then 1-72). Then they were orally given the stimulus word, and they wrote the response on the numbered slip of paper and put the slip of paper on the bottom of the stack. This procedure was repeated in each trial. After each association task, packets of paper were collected. The packets for the two conditions were matched according to the subject number.

\section{RESULTS AND DISCUSSION}

Scores were derived from subjects' responses to test words. The number of different responses (from one to five) was determined for each test word. These scores were summed over 12 test words, yielding the rigidity score; a score of 12 corresponded to the maximum possible rigidity, and a score of 60 , to the maximum possible flexibility. Free association and controlled association scores were determined separately.

The mean rigidity score in the free association task was 28.89 , and that in the controlled association task was 28.30. The respective standard deviations were 11.21 and 12.20. The respective total ranges were 13-57 and 12-59. The product-moment coefficient of correlation between the free and controlled association rigidity scores was $.626(\mathrm{p}<.001)$, and the coefficient of determination was .392 .

The descriptive results show practically no difference in rigidity scores between free and controlled association, either in terms of means or in terms of standard deviations. However, the two association tasks were intentionally confounded with test order (free association task was run first), since the purpose was to establish correlation. The descriptive statistics do indicate that the discriminant validity of both tests seems satisfactory.

The correlation between free and controlled association was highly significant, with more than $33 \%$ of the variance shared between the two variables, signifying that both tests depicted a common factor of associative rigidity.

In conclusion, the degree of recurrence of the same associative response to an identical stimulus word appears to be a sensible measure of associative rigidity (or associative stereotypy) and could be used as a useful dependent measure in the study of factors that affect the stereotypy of human associative processes. The concept of stereotypy as used in this study should be distinguished from the "word stereotypy score" used as a measure of total number of high-frequency words produced in an association test (see Vellutino, 1971).

\section{REFERENCES}

Johnson, R. E. Remembering of word associations. Journal of General Psychology, 1973, 88, 99-103.

Paivio, A., Yuille, J. C., \& Madigan, S. A. Concreteness, imagery, and meaningfulness values for 925 nouns. Journal of Experimental Psychology Monograph Supplement, 1968, $76(1$, Pt. 2), 1-25.

Slak, S., Shaffer, J. I., \& Barone, N. C. Sequence redundancy under conditions of randomization and spontaneous activity. Bulletin of the Psychonomic Society, 1982, 19, 256-258.

VELLUTINo, F. R. Verbal response stereotypy as a function of psychological and physiological drive. Perceptual and Motor Skills, 1971, 33(3, Pt. 1), 851-858.

(Received for publication October 27, 1982.) 